\title{
From Autocracy to Empowerment: Teams with Shared Leadership Perceive their Coaches to be Better Leaders
}

Katrien Fransen, Niels Mertens, Stewart T. Cotterill, Gert Vande Broek \& Filip Boen

To cite this article: Katrien Fransen, Niels Mertens, Stewart T. Cotterill, Gert Vande Broek \& Filip Boen (2019): From Autocracy to Empowerment: Teams with Shared Leadership Perceive their Coaches to be Better Leaders, Journal of Applied Sport Psychology

To link to this article: https://doi.org/10.1080/10413200.2019.1617370

Accepted author version posted online: 10 May 2019.

Submit your article to this journal $\pi$

View Crossmark data $₫$ 
Running Head: High-Quality Coaches Opt for Shared Leadership

From Autocracy to Empowerment: Teams with Shared Leadership Perceive their Coaches to be Better Leaders.

Katrien Fransen ${ }^{1}$, Niels Mertens ${ }^{1}$, Stewart T. Cotterill ${ }^{2}$, Gert Vande Broek ${ }^{1}$, \& Filip Boen ${ }^{1}$

${ }^{1}$ Department of Movement Sciences, KU Leuven, Leuven, Belgium

${ }^{2}$ School of Psychology, Sport, and Physical Activity, AECC University College, Bournemouth, Dorset, UK 


\begin{abstract}
Some sports coaches believe that empowering the players in their team can undermine their own leadership status. In business organizations, however, recent theorizing on shared leadership refutes this belief by suggesting that the most effective leaders engage in behaviors to strengthen the leadership qualities of their followers. The present study sought to investigate this perspective within sports teams. Social network analyses were performed to study the leadership structure within a stratified sample (across sport, gender, and competitive level) of 64 sports teams, encompassing 64 coaches and 776 players. Next, we related the perceived leadership quality of the coaches to specific characteristics of their teams' leadership networks. The results highlighted that the perceived leadership quality of the coach was positively related to the density of the team's leadership networks (i.e., the average leadership qualities of all players). This finding held for the four leadership roles of task, motivational, social, and external leadership. This outcome suggests that the best coaches are the ones who adopt a shared leadership approach and who strengthen the leadership quality of their players. However, our findings also suggest that the perceptions of coaches and players on the team's leadership dynamics often differ. Consequently, coaches could benefit from the analysis of leadership networks to gain insight in their team's leadership structure. Based on this knowledge, coaches could then correctly identify the best leaders in the team, as perceived by the other team members. By creating and developing these leaders, coaches then become better leaders themselves.

Keywords: Athlete leadership, peer leadership, social network analysis, leadership development, leader satisfaction
\end{abstract}




\section{0-word lay summary}

Some sports coaches feel that empowering the players in their teams undermines their own leadership status. This study investigates the legitimacy of this perception within 64 sports teams. Our findings provide evidence for the opposite view; by creating and developing leaders in their teams, coaches are perceived as better leaders themselves. 
From Autocracy to Empowerment: Teams with Shared Leadership Perceive their Coaches to be Better Leaders.

\section{Leadership in Sports Teams}

High-quality leadership at all levels within sports organizations (i.e., club boards, performance directors, coaches, and athletes) is considered to be crucial for the growth and effectiveness of sports teams (Arthur, Wagstaff, \& Hardy, 2017; Welty Peachey, Zhou, Damon, \& Burton, 2015). Coach leadership ${ }^{1}$ in particular has been shown to be an important driver behind a teams' competitive advantage (Arthur \& Lynn, 2017; Mallett \& Lara-Bercial, 2016; Thelwell, Wagstaff, Rayner, Chapman, \& Barker, 2017). More specifically, highquality coaches have been reported to increase players' confidence in the team's capacities (Hampson \& Jowett, 2014), strengthen the players' identification with the team and the team's cohesion (De Backer et al., 2011; Fransen, Decroos, Vande Broek, \& Boen, 2016a), improve the team's psychological climate and the proactivity of the players (Van Puyenbroeck, Stouten, \& Vande Broek, 2018), and nurture players' competence satisfaction and their intrinsic motivation, thereby enhancing the team's functioning and improving the team's performance (Fransen, Boen, Vansteenkiste, Mertens, \& Vande Broek, 2018).

However, it is important to recognize that the coach is not the only source of leadership in the team.

The last decade in sports-related leadership literature has been characterized by a rapid growth in studies on athlete leadership. Loughead, Hardy, and Eys (2006, p. 144) defined an athlete leader as "an athlete occupying a formal or informal leadership role influencing team

\footnotetext{
${ }^{1}$ Coach leadership can be defined as a behavioral process that is used to increase athlete performance and satisfaction (Chelladurai \& Riemer, 1998). With respect to the distinction that organizational researchers make between leadership and coaching, we apply the definition of Hackman and Wageman (2005) to the sports context. In this regard, sports coaches do not only coach their individual athletes and team as a whole to improve their effectiveness. In addition, they engage in activities such as structuring the team, establishing the team's purposes, and providing the necessary resources. As a result, their core tasks reach beyond purely coaching activities and they can therefore be defined as 'leaders,' which is a more inclusive term compared with the rather strict term 'coaches'. The same reasoning holds for athletes within the team who occupy a leadership role.
} 
members towards a common goal." Fransen, Vanbeselaere, De Cuyper, Vande Broek, and Boen (2014) distinguished between four different leadership roles that players can occupy in a team; two leadership roles on the field (i.e., a task leader and a motivational leader) and two roles off the field (i.e., a social leader and an external leader). The full definitions of these leadership roles are presented in Table 1. For the fulfillment of these leadership roles, previous studies highlighted the importance of looking beyond the team captain. In fact, it is often the case that informal leaders (i.e., athletes who do not occupy a formal leadership position but are perceived as leaders by their teammates as a results of the interactions occurring within the team) are often perceived by their teammates as being a leader on each of the four roles compared to the team captain (Fransen et al., 2015b; Fransen et al., 2014).

A significant body of research has demonstrated that these leaders within the team (i.e., athlete leaders) are important drivers of the team's success (for a review on athlete leadership, see Cotterill \& Fransen, 2016). To illustrate, high-quality athlete leadership has been related with the following outcomes: increased team identification and team confidence (Fransen et al., 2016a), stronger task and social cohesion (Fransen et al., 2016a; Loughead, Fransen, Van Puyenbroeck, Hoffmann, \& Boen, 2016), improved team resilience when facing setbacks (Morgan, Fletcher, \& Sarkar, 2013), and ultimately also a better team performance (Crozier, Loughead, \& Munroe-Chandler, 2013; Fransen et al., 2017). In line with previous research in business organizations (Pearce \& Conger, 2003) and schools (Muijs \& Harris, 2003), contemporary research in sports teams suggests coaches should develop a structure of shared leadership, in which the coach and the athlete leaders take the lead together for the good of the team. Distinct from the traditional notion of top-down or vertical leadership, shared leadership (also termed collective or distributed leadership) can be described as a group-level phenomenon in which the leadership role is shared among team members resulting in horizontal and upward influence (Fletcher \& Arnold, 2015; Pearce \& Conger, 
2003). Moreover, drawing upon the original conceptualization by Gibb (1954), shared leadership can be conceptualized along a continuum based on the number of leadership sources (i.e., team members) having a high degree of influence in a team (Carson, Tesluk, \& Marrone, 2007). Anchoring the low end of the continuum are cases in which team members follow the leadership of a single individual (e.g., the team captain). In contrast, at the high end of the shared leadership continuum are teams in which most, if not all, team members are perceived as good leaders by one another.

\section{The Barriers to Player Empowerment}

Despite the evidence supporting the benefits of shared leadership, not all coaches seek to empower the players in their team and formally appoint athlete leaders. Cushion, Ford, and Williams (2012, p. 1638) added that "some coaches use seemingly athlete-centered approaches, although evidence would suggest that many actually only present 'an illusion of empowerment', so athletes 'buy into' their potentially contradictory agenda."

Given all the associated benefits of shared leadership, it is a concern that coaches are not more eager to strengthen the leadership in their team. One potential explanation for this could be that research on athlete leadership is still relatively new and many coaches may not yet be aware of the reported benefits. Ntoumanis and Mallett (2014) further suggested that coaches are used to adopt a controlling coaching style (with no room for players' voice) but are not aware of the long-term adverse consequences of such controlling behaviors (e.g., amotivation, attrition, and psychological illness). Although this lack of knowledge might indeed be one of the explanations, it is also possible that coaches encounter other barriers that can make them reluctant to empower the players in their teams. Example of potential barriers include: the idea that players prefer a directive coaching style, the fear of losing visibility as a leader, the fear of losing control, the external pressure to perform on the short-term, the fear of being perceived as lazy, the idea that in time-pressuring situations only autocratic 
leadership is effective, or in general the typical culture of hierarchical controlling leadership (Ntoumanis \& Mallett, 2014; Vroom \& Yetton, 1973).

To our knowledge, no research to date, within sports teams has focused on these potential barriers that can hinder the development of a shared leadership structure. Given the significant contextual overlap between organizations and sport (e.g., teams headed by a formal leader, focus on competitive advantage, clear objectives, need for cooperation), it is reasonable to expect that knowledge will generalize from work (or education or military or other organizational contexts) to sport or conversely (Day, Gordon, \& Fink, 2012; Weinberg $\&$ McDermott, 2002). As such, it may be that initial approaches in sporting contexts need to be adapted from successful approaches utilized in other performance contexts (see Cotterill, 2017 for an overview).

Preliminary research in educational settings (Muijs \& Harris, 2003) and organizational contexts (Wheatley, 1997) suggests that there can exists a fear and uncertainty amongst formal leaders, that can result in an overemphasis on control as the prime mechanism in maintaining bureaucratic and hierarchical leadership structures. These authors conclude that in these settings many leaders have consistently over the years chosen control rather than productivity. For coaches of sports teams, one of the potential barriers might be the fear that empowering their players might undermine their own leadership position in the team (Ntoumanis \& Mallett, 2014). Another possible fear for the coaches might be the idea that players might perceive the coach who empower their players to be weak and incompetent given that in a shared leadership structure coaches will ask for players' input rather than dictating the approach adopted. These potential barriers, and the current lack of research exploring this issue in sport underpins the main research question that the present paper addresses: 
Research question 1: Does the implementation of a shared leadership approach devalue the perceived leadership quality of coaches as perceived by their players?

To formulate our hypothesis, specific literature relating to education and organizational contexts was evaluated. In two case studies by Little (1995) school principals who introduced shared leadership and empowered their teachers were interviewed. These principals suggested that the development of shared leadership had a positive influence on teaching in the school. In business organizations, though, the existing evidence is more equivocal. While some studies suggest that employees who feel empowered are more likely to have higher levels of trust in their leaders (Huang, 2012; Moye \& Henkin, 2006; Zhu, May, \& Avolio, 2004), other studies have not reported this positive link between shared leadership and perceptions of the leader (Bartram \& Casimir, 2007).

The sports context lacks evidence of the direct link between shared leadership and the perceived quality of the coach. Nevertheless, recent evidence did show that autonomysupportive and participative coaching styles, which can be linked to the implementation of a shared leadership structure, were moderately and positively related with coach satisfaction (Delrue et al., 2019). Based on these preliminary findings we formulated the following hypothesis for each of the four leadership roles (i.e., task, motivational, social, and external leadership).

Hypothesis: Coaches of teams who have adopted a shared leadership structure within a specific leadership role (i.e., having high-quality task, motivational, social, or external team leadership) are perceived as better leaders in that role by their players.

\section{How to Implement an Effective Structure of Shared Leadership?}

Based on the research evidence outlined above, shared leadership may have many benefits, ranging from team functioning, to well-being and performance (Cotterill \& Fransen, 2016). If coaches can be encouraged to adopt a shared leadership approach, the next step 
would be to examine the most effective way to implement an impactful shared leadership structure. A crucial prerequisite to implement such a structure in sports teams would be for the coach to be able to identify the best leaders on task, motivational, social, and external leadership.

In today's sports culture, coaches are still the main decision-makers when it comes to appointing leaders within their teams (e.g., when appointing a team captain; Gould, Voelker, \& Griffes, 2013). Although coaches often claim that they have the best insight in their team's leadership structure, this may not be true. For example, Gulak-Lipka (2017) questioned the strategy to let coaches designate the athlete leaders considering that the team might not fully accept this choice if they do not perceive the designated person as a leader. If the appointed leader does not have the support of the team, his/her impact will be limited and effective shared leadership is far off. Also Fletcher and Arnold (2015) highlighted the critical role that the perceptions of followers play in determining leader effectiveness. Gulak-Lipka (2017) therefore clearly argued for providing voice to the players in the leader selection process.

The work of Fransen et al. (2014) corroborates this suggestion as their findings showed that almost half of the team captains, who are usually selected by the coach, were not perceived by the players as best leaders in any of the four leadership roles; not on the field as task or motivational leaders, and not off the field as social or external leaders. Instead, other players in the team were perceived as the best (informal) leaders by their teammates.

These findings suggest that the current leadership selection processes in sports teams are not as effective as they could potentially be. This might be problematic as evidence suggests that if the perceptions of coaches and players on the team's leadership do not align, and the coach assigns leaders that are not perceived as leaders by the players, team functioning is compromised (Gulak-Lipka, 2017). Therefore, the second key question that the 
present paper addresses the overlap between perceptions of coaches and players when it comes to the team's leadership:

Research question 2: Is there a high overlap between the perceptions of the coach and the perceptions of the players on the team's leadership?

Given the limited evidence existing on this topic, this research question is considered to be exploratory and we therefore decided not to formulate an a priori hypothesis.

\section{Method}

\section{Procedure}

In this study we collected a random stratified sample of 64 sports teams, encompassing 16 teams from four different sports (i.e., soccer, volleyball, basketball, and handball). Within each sport, we ensured an equal distribution between male and female teams (i.e., eight male teams and eight female teams in each sport). Within each of these categories we ensured an equal contribution of teams from the highest leagues of the competition (i.e., national level) and teams of the lower competition leagues (i.e., provincial or regional leagues). In order to obtain this stratified sample of 64 teams, 130 coaches were invited via email to participate in our study, resulting in a response rate of $49 \%$.

After approval from the coach, a research assistant attended a training session of each team, explained the purpose of the study, and asked all players if they were willing to participate in the study. Confidentiality of responses was guaranteed and participants were told that they had the opportunity to withdraw participation at any time. After giving informed consent, players were asked to complete the questionnaire. The research assistant was present to answer questions. Upon completion, all questionnaires were assembled in a closed envelope by the researcher. The APA ethical standards were followed in the conduct of both studies and approval was obtained of the ethical committee of the first author's university (G- 
201502 169). No rewards were given for participation in the study, except for a report by email, sent to all participating players and coaches, with the general study findings.

\section{Participants}

In total, this study included 776 players and 64 head coaches of whom 263 belonged to soccer teams (i.e., 247 players and 16 coaches), 177 to volleyball teams (i.e., 161 players and 16 coaches), 150 to basketball teams (i.e., 134 players and 16 coaches), and 250 to handball teams (i.e., 234 players and 16 coaches). The response rate within the teams ranged between $81 \%$ and $100 \%(M=94.58 \% ; S D=.08)$. In total, 380 male players and 396 female players participated in the study. The coaches were all male except for one female coach, thereby reflecting the male majority of coaches in Flanders. In total, 460 of the participants were active at high competitive level and 428 were active at low competitive level. The players were on average 23.75 years old $(S D=6.32)$ and had on average 14.74 years of experience in their sport $(S D=6.65)$. They were playing on average $4.99(S D=4.91)$ years for the team, of which $2.01(S D=.16)$ with the current coach. The coaches were on average 43.40 years old $(S D=10.58)$ and had on average $14.68(S D=8.63)$ years of experience in coaching.

\section{Measures}

Generation of leadership networks. To obtain a reliable measure of the leadership quality of the coach and the players, we followed the standard procedure that has been recommended in recent reviews of the field (e.g., Cotterill \& Fransen, 2016), and that has been validated in several studies in the field (Fransen et al., 2015a; Fransen et al., 2015b; Loughead et al., 2016). Three features characterize this procedure. First, we calculate the leadership quality of all team members (visualized by a network), instead of focusing on the formal leaders only (e.g., the team captain) as previous research indicated that the captain is often not seen as the best leader in the team (Fransen et al., 2014). Second, since being a leader does not automatically entail being a good leader (i.e., being seen to display effective 
leadership), we chose to focus on the leadership quality. Third, the leadership quality of an individual is based on the perceptions of the other team members, which is preferred to using self-ratings.

More specifically, to obtain this peer-rated leadership quality assessment, we asked all team members to carefully read the definitions of the four leadership roles (as presented in Table 1). After each of the leadership roles, we asked participants: "Please rate the leadership quality of each of your teammates and your coach in this specific leadership role on a scale from 1 (very bad leader) to 7 (very good leader)". To facilitate the process for participants, the names of all team members were filled out in advance based on the team roster.

We consciously opted for subjective leadership perceptions instead of for actual leadership behaviors. As Shaver (1975) indicated: “an individual's perception of a situation is more important than the objective situation in determining one's feelings and actions." In other words, the perceptions of athletes with respect to the leadership quality of their teammates is more important than the actual leadership behaviors of those teammates. As a result, athletes' subjective perceptions will determine whether athletes will follow their leaders, and thus whether a structure of shared leadership will be successful.

For each team, this data collection resulted in an $N \times N$ matrix (with $N$ being the number of team members), where the rows reflect the scores given by a particular rater, and the columns reflect the scores received by all team members. In line with previous guidelines (Fransen et al., 2015b), the diagonal entries are omitted given that the self-perceptions of participants (i.e., ratings of their own leadership quality) are not taken into account. Social network analyses of the resulting leadership networks provided measures at both the individual and the team level.

Individual-level network measures. First, we identified the leadership quality of all team members (i.e., players and the coach) on the four leadership roles. To do so, we 
calculated each participant's indegree centrality on each of the four leadership roles. In network terms, indegree centrality is a node-specific measure (with nodes referring to the players) that reflects the average strength of a node's incoming ties (i.e., the average leadership quality of an athlete, as perceived by the players). This measure reflects leaders' importance in the team and their capacity to influence other team members, therefore being the best reflection of a person's leadership quality (Fransen et al., 2015b; Hoppe \& Reinelt, 2010). It is important to note that only the perceptions of the players are taken into account to calculate both players' and coaches' perceived leadership quality. The perception of the coach on the leadership quality of the players constituted a different variable in order to answer our second research question.

Team-level network measures. In line with previous studies (Fransen et al., 2015a), two team-level SNA measures were distinguished. First, we calculated the leadership network density for each team for each of the four leadership networks (i.e., task, motivational, social, and external leadership), using the same procedure for valued networks as described by Sparrowe, Liden, Wayne, and Kraimer (2001). More specifically, the density of a network was calculated by summing the values of all relations and dividing this result by the number of all possible relations. As such the values of network density vary between the end points of the scale; in this case between 1 (very low-quality team leadership) and 7 (very high-quality team leadership). Given that we aimed to obtain insight in the team's internal leadership quality, we did not take into account the coach data for these analyses. The networks used to calculate the leadership density thus rely on the perceptions provided by players about players. High leadership density scores then characterize the teams with on average highquality athlete leadership, whereas low density scores characterize teams with on average low-quality athlete leaders. 
Second, the use of network centralization has been recommended to assess the extent to which the leadership is shared amongst the entire team (Mayo, Meindl, \& Pastor, 2003; Small \& Rentsch, 2010). In essence, centralization can be considered as a measure of variance in the degree centrality measures of a network and represents a measure of compactness (for the formula see Mayo et al., 2003, p. 204). Because this study focused on participants' indegree (rather than outdegree) centrality in the leadership quality networks (as only the incoming ties matter for one's leadership quality), we assessed each network's indegree centralization. To be able to distinguish a truly vertical leadership structure (with the coach as the only leader) from structures with more shared leadership, the coach data were essential to include in the network for calculating network centralization. The values of network centralization range between 0 and 100, where 0 represents a non-centralized network (i.e., when all members are perceived to participate equally in displaying leadership behaviors) and 100 represents a highly centralized network (i.e., when leadership behaviors revolve around a single individual). Previous research examining centralization scores of leadership networks in sports teams demonstrated centralization values between $13.18 \%$ and $62.73 \%$ (Fransen et al., 2015a).

In order to truly grasp the structure of a team's leadership network, it is important to look at the network's density and centralization simultaneously. To illustrate, a low centralization score might point at shared leadership, but when the density is also low it rather characterizes a team in which none of the players engage in leadership. Teams with highquality shared leadership should thus be characterized by the combination of a high network density (high overall leadership quality) and a low network centralization (i.e., leadership is spread throughout the team) (D’Innocenzo, Mathieu, \& Kukenberger, 2016; Mayo et al., 2003). However, the latest leadership research suggests that the relation between network centralization and team effectiveness is curvilinear (Eys, Loughead, \& Hardy, 2007; Fransen, 
Delvaux, Mesquita, \& Van Puyenbroeck, 2018; Gockel \& Werth, 2010). More specifically, an intermediate level of shared leadership is preferable to having either too few leaders or too many.

To obtain an overview of the leadership structure in all participating teams, we created two categories with an equal number of teams having relatively high and relatively low leadership network density and three equal categories of teams with high, moderate, and low leadership network centralization (if there are indeed teams that belong to those different categories). The resulting six combinations encompass the most important possible leadership structures and can subsequently be related to coaches' perceived leadership quality.

\section{Results}

\section{Descriptive Data}

Table 2 presents the means, standard deviations, and correlations between all variables of interest. The leadership network densities cover a broad range and vary between 2.18 and 6.00 on a scale from 1 to 7 for the different leadership roles. The network centralizations, on the other hand, which can vary between 0 and 100, only cover the lower half of the scale and vary between 6.54 and 47.09 on the four leadership roles. We can thus conclude that none of the teams included in our study had a clear hierarchical structure with the coach (or a player) holding all the leadership in a specific role. Instead, all teams demonstrate structures of shared leadership, ranging from structures in which all team members demonstrate leadership to an equal extent (low centralization), to teams in which a selected group of leaders occupies the leadership positions (moderate centralization).

It is noteworthy that the correlations between the different leadership roles are moderate to high, suggesting that when coaches are perceived as good leaders in a specific role, they also have a higher chance of being perceived as good leaders in other leadership roles. The same holds for the average leadership quality in the team; if a team has high-quality 
leadership in one role, it appears more likely that the team also demonstrates high-quality team leadership in the other leadership roles.

\section{Research Question 1: Are Coaches Who Create More Leaders Perceived as Better}

\section{Coaches?}

To answer this question, we first analyzed the correlations between the coaches' leadership quality in a particular role and the team's leadership quality in that role, reflected by the leadership network density. The findings presented in Table 3 show that these correlations vary between .26 and .37 for the four leadership roles, all being statistically significant. We can therefore conclude that the higher the level of leadership quality perceived in the team, the more the coach is perceived to be a good leader by the players. This finding is in line with $\mathrm{H} 1$ that the best leaders lead teams that have more leaders

The network centralizations provide insight to whether it is important for coaches to develop the leadership qualities of all members in the team (low centralization) or just of a selected group of leaders (moderate centralization). The correlations in Table 2 show a (albeit non-significant) trend in the negative direction for motivational and social leadership (i.e., suggesting that if the leadership is shared amongst multiple leaders in the team, the better the leadership of the coach is perceived to be).

However, we should keep in mind that neither the density, nor the centralization on their own provide profound insight into the leadership structure. To obtain a more complete insight into the structure, we should instead look at the density and the centralization of the leadership network simultaneously. Therefore, we distinguished between four combinations based on high/low density and moderate/low centralization (as no teams were characterized by a highly centralized network structure). The perceived leadership quality of the coach in each of these categories is presented in Table 4. Taking into account all data simultaneously, the findings highlight that teams in which a select group of leaders show high leadership 
quality (i.e., networks with high density and moderate centralization) perceive their coaches as best leaders, which supports H1. This finding holds for task, motivational, and social leadership. For example, teams with a high-quality task leadership team will also perceive their coach to be a good task leader. The only exception relates to external leadership. Although a high network density is also essential for the coach to be perceived as a good external leader, coaches of teams in which external leadership is spread throughout the team (i.e., low centralization) score slightly better on their perceived external leadership quality than coaches of teams with a strong external leadership team (i.e., moderate centralization).

Generalizability of our findings. Given that our sample was stratified with respect to sports, male and female teams, and competitive level, we were able to test whether our findings are valid in each of these categories. Table 3 presents the correlations between leadership quality and leadership density and centralization for each of these categories. Table 4 presents the detailed results for the four combinations of density and centralization.

Sports. With respect to the sports, we can conclude that in particular soccer shows strong correlations between the density in a leadership network and the leadership quality of the coach in the associated role, with correlations ranging from .36 to 65 for the four different leadership roles. Also in handball strong correlations were reported for social and external leadership. In volleyball, density appears not to be so strongly decisive for the coach's leadership quality. However, for motivational leadership it seems that the more motivational leaders in the volleyball team (i.e., low centralization), the better the coach is perceived as motivational leader. It is important to note that none of the sports show a low network density, indicating that coaches of teams with low-quality leadership (or with only the coach as hierarchical leader) are not perceived to be good leaders.

The number of teams per sport was too low to provide a reliable analysis on the different combinations of density and centralization with respect to sports. The observed 
differences between sports when looking at the densities and centralizations separately suggest that our findings are not completely generalizable to the different sports and that sport-specific characteristics should be taken into account.

Male and female teams. With respect to the differences between male and female teams, the results in Table 3 point at stronger correlations in female teams, indicating that the perceived leadership quality of the coaches of female teams is more strongly related to the leadership density in the team, with correlations ranging between .34 and .46 . A lower centralization (i.e., leadership spread throughout the team) seems also important for motivational, social, and external leadership. Also male teams show a positive correlation between their coach's leadership quality and the density of all networks, although the correlations are lower than for female teams (between .17 and .32 for the four roles). It is noteworthy that in male teams, coaches are perceived as better external leaders when the external leadership within the team is centralized, whereas for female teams it seems better to have multiple external leaders.

When looking at the combinations of density and centralizations in Table 4, we can conclude that coaches of male teams appear to be perceived as the best leaders when their teams have a leadership structure with high density and moderate centralization in task, motivational, and social leadership. Only for external leadership, coaches in teams with lower but centralized quality of external leadership scored best. By contrast, the best coaches of female teams led teams having leadership structures with high density and low centralization in task, social and external leadership. Only for motivational leadership, coaches of teams with low density and low centralization scored best, which is in contrast with $\mathrm{H} 1$.

Competitive level. When looking at the differences between high and low competitive level, it is worth noting that at a high level, the average quality of the team's task and external leadership (i.e., reflected by the density) seems predictive for the coach's leadership quality. 
For motivational leadership it seems important that the leadership quality is spread throughout the team (i.e., reflected by centralization). While the team's social leadership does not seem to be related with the coach's social leadership quality in high-level teams, this relation is present for low-level teams. More specifically, coaches of teams with high-quality social leadership (i.e., high density) that is spread throughout the team (i.e., low centralization) are perceived by the team members as being the best social leaders. Also for the other leadership roles, low-level teams show a strong relationship between the densities of their leadership networks and the perceived leadership quality of the coach, with correlations ranging between .34 and .46 .

Looking at the combinations of density and centralization in Table 4, it can be concluded that coaches of high-level sports teams are perceived as better task, social, and external leaders when their teams show high-leadership quality in that particular role. For task and external leadership, coaches are perceived as better leaders when the leadership is spread throughout the team. By contrast, for social leadership, it seems better to have only a limited group of high-quality leaders. The positive relationship between leadership density and the coach's perceived leadership quality did not emerge for motivational leadership at a high competitive level. At low competitive levels, coaches were perceived as best task, motivational, and external leaders when their teams had a selected group of leaders with highquality leadership skills. Only for social leadership, coaches scored better when the highquality leadership was spread throughout the team. The findings reported here suggest that empowering the leaders within the team is not at the expense of the coach's perceived leadership quality.

\section{Do Players Agree with Their Coach's Perceptions on the Best Leaders in the Team?}

Our second research question addressed the extent to which the perceptions of the coach on the team's leadership are aligned with the perceptions of the players. To do so, we 
calculated the correlations between the score provided by the coach on a player's leadership quality and the indegree centrality of that same player (i.e., how other teammates perceive that player's leadership qualities). These analyses were conducted for each of the four leadership roles. The results are reported in Table 5 .

We can conclude that for each of the leadership roles the correlations between the perceptions of the coach and the perceptions of the players on the team's leadership are only moderate (with correlations ranging from .52 to .61 ). One could argue that in order to identify the right leaders, it is not necessary for coaches to have a perfect insight into the entire team. Instead, it might be sufficient to be able to identify the best leader of the team in each of the four roles. To obtain a greater insight into this capacity of coaches, we examined whether the best leader indicated by the coach was also highlighted by the players as best leader (i.e., having the highest indegree centrality), second best leader, third best leader, or not a part of the players' top 3. If the coach provided multiple players in the team with the same highest score (regardless of the absolute value of that score), all were taken into account as leaders.

The findings presented in Table 6 highlighted that only in one third of the teams the coach and the players agreed on the perceived best leader in the team, with percentages ranging from 23.8 to 33.6 for the four leadership roles. Interestingly, the coaches seem to have the least insight in the team's social leaders, with only $23.8 \%$ of the social leaders identified by the coach also being the best social leader according to the players.

Although the error rate of coaches is quite high, we should highlight that the majority of the leaders appointed by the coach are still included in the player-rated top three. In other words, they are still perceived as good leaders by the team and will be able to effectively lead the team. However, in a significant number of teams (ranging between $29.7 \%$ and $44.4 \%$ for the four roles), the leaders indicated by the coach were not included in the player-rated top three, suggesting that the acceptance of the team might be insufficient. In particular for social 
leadership, almost half of the social leaders (44.4\%) indicated by the coach were not perceived as good social leaders by the players.

Generalizability of our findings. The stratified sample with respect to sports, male and female teams, and competitive level allowed us to test whether our findings are valid in each of these categories. The correlations in Table 5 between perceptions of coaches and players on the team's leadership are very similar across the different sports (with volleyball having slightly higher correlations than the other sports), both for male and female teams (with male teams reporting a slightly better overlap than female teams), and for high and low competitive level.

When considering the coaches' insight into the perceived best leader in the team, volleyball coaches performed best, as $46.4 \%$ of the coaches were able to identify the same best leader as the players. The smaller team size in volleyball, compared to soccer and handball might underpin this finding. Furthermore, coaches of male teams performed slightly better than coaches of female teams, although this did not hold for motivational leadership. Finally, coaches at high competitive levels were better in identifying the perceived best leader in their teams, especially with respect to external leadership. Nevertheless, also at a high competitive level we should emphasize that $29.1 \%$ of the task leaders, $32.9 \%$ of the motivational leaders, $38.3 \%$ of the social leaders, and $14.5 \%$ of the external leaders indicated by the coach are not included in the top three of leaders as perceived by the players. These findings suggest that coaches do not always make a choice that aligns with player perceptions when identifying the leaders who are accepted as leaders by their teammates. 


\section{Discussion}

The current study aimed to contribute to the literature on shared leadership in sports teams by addressing two specific research questions. First, to investigate whether the implementation of a shared leadership structure undermines the perceived leadership quality of the coach, as this might be an important barrier for coaches to empower their players. Second, to explore whether the coach has adequate insight in the team's leadership to appoint the best leaders, according to player perceptions.

\section{From Power to Empowerment}

The results highlighted that the correlations between the coaches' leadership quality on a particular leadership role (as perceived by the players) positively related to the team's overall leadership quality on that role (measured by the network density). In other words, teams with better leadership within the team perceive their coach to be a better leader. This finding held to be true for each of the four leadership roles. Next, we took into account the extent to which leadership is spread throughout the team (as measured by network centralization). The results revealed that for task, motivational, and social leadership, the best coaches led the teams in which the leadership is spread amongst a limited number of leaders, as indicated by a moderate network centralization. Only for external leadership, the perceived leadership quality of the coach benefited from the external leadership being spread across the entire team (indicated by a low network centralization).

Our findings thus support earlier work in organizational settings suggesting that psychological empowerment by the supervisor positively predicts employees' trust in that supervisor (Huang, 2012; Moye \& Henkin, 2006; Moye, Henkin, \& Egley, 2005; Sallee \& Flaherty, 2003). Huang (2012) relied on the framework of the social exchange theory (Blau, 1964) to explain this relationship as a dynamic exchange of benefits between leaders and followers. More specifically, the norms of reciprocity (Gouldner, 1960) imply that when team 
members receive extrinsic or intrinsic rewards from their supervisors, they are obliged to reciprocate by providing some benefit in return. In the context of empowering team members, previous research highlighted that when organizational leaders shared and delegated control to their followers, this empowerment could be seen as a social reward provided by that leader (Whitener, Brodt, Korsgaard, \& Werner, 1998; Zhu et al., 2004). As a result, followers' trust in the leader was likely to emerge as reciprocation or payback. The same reasoning might underpin our findings in sports teams. Coaches who empower their players are signaling to these individuals that they are trusted and competent in taking the lead. The players may in turn reciprocate this psychological reward by investing an attitude of trust in their coaches, reflected by a higher perceived leadership quality.

The stratified sample recruited for this study allowed us to test the generalizability of our findings across sports, male and female teams, and high and low competitive level. Some interesting differences emerged. For example, within soccer the perceived quality of the coach was much more dependent on the team's leadership quality (reflected by the network density) than in other sports. A potential reason underpinning this finding could be that the playing field of soccer teams is much larger than the field of volleyball or basketball. As a result, the impact of the coach during the game is limited and it is even more important to have highquality leadership on the field. These findings align with earlier observations of Fransen et al. (2016b) revealing that in particular within soccer, which is played on a large field with relatively fixed positions, the best leaders played at positions that were most central on the field, while this relationship was much weaker in other sports. Taking the coach into account, our findings add that for soccer coaches it is even more important to implement a shared leadership structure and empower their players in order to be perceived as a better leader themselves. Having good leaders on the field is thus a more effective option for soccer coaches to translate their vision and strategy effectively onto the field of play. 
Furthermore, our findings highlighted that the importance of having a high network density (i.e., the average leadership quality) held across both male and female teams. On the other hand, male and female teams differed with respect to how this leadership was spread within the group: while coaches of male teams were perceived as better leaders if that leadership was spread amongst a limited number of leaders (i.e., moderate centralization), coaches of female teams were generally perceived as better leaders if the leadership was spread throughout the entire team (i.e., low centralization). Future studies should test whether these discrepant findings hold in other team sports, settings, and cultures.

Finally, we can conclude that it appears that high-quality team leadership (i.e.., reflected by the density) is important at both high and low competitive level for coaches to be perceived as good leaders. Whether this high-quality leadership should be spread throughout the team or occupied by a limited group of leaders (i.e., reflected by the centralization) depends on the competitive level and the leadership role under investigation. The limited variation in centralization scores could also underpin these incongruences.

\section{Do Coaches and Players Agree on Who to Appoint as Leaders?}

When implementing a structure of shared leadership, an essential element is identifying the best leaders in the team. To date, coaches have often taken charge in appointing the leaders in their team (Gould et al., 2013). However, it is crucial to understand whether coaches have an adequate insight into their team's leadership needs to make the optimal leadership choices. Assuming that athlete leaders are only able to truly impact the team when they are accepted as leaders by their teammates (Gulak-Lipka, 2017), the overlap between perceptions of coaches and players on the team's leadership should be substantial in order to justify the coach being the main decision-maker.

Our findings highlight only moderate correlations between the perceptions of the coach and those of the players with respect to the team's leadership. More specifically, we 
found that only in one third of the teams, coaches and players agreed on the best leader in their team. It should be noted that, although coaches regularly appoint leaders that are not perceived as the best leader by their teammates, these leaders are usually still included in the top 3 proposed by the players, meaning that it is likely that these leaders would still be accepted as leaders by their team. Nevertheless, there is a substantial number of teams (ranging between $29.7 \%$ and $44.4 \%$ for the four roles), in which the leaders indicated by the coach were not included in the player-rated top three, suggesting that the acceptance of the team is likely to be insufficient to obtain effective leadership.

Moreover, while coaches seem to have a good insight into the task and motivational leadership qualities within their teams, the external leadership qualities and in particular the social leadership qualities seem to remain obscured for the coach. These findings held for male and female teams active at both high and low competitive level. Coaches at high level only performed better when identifying the best external leader in the team. This makes sense given the more visible relations with media, sponsors, and fans at this higher level, compared to lower-level teams. We can therefore conclude that coaches often do not have sufficient insight in their team's leadership in order to identify the players who can best meet the leadership needs of the team.

\section{Practical Implications}

The present study highlights that developing a structure of shared leadership is not related with an associated devaluation of the leadership quality of the coach, as perceived by the players. In contrast, in most teams a positive relationship was observed between structures of shared leadership and the perceived leadership quality of the coach. As such, this study removes an important barrier that might hold coaches back from adopting a shared leadership approach. 
When appointing the leaders in their team, it is essential for coaches not only to rely on their own insights, but also to give their players a voice in this decision process. The technique of Shared Leadership Mapping (Fransen et al., 2015b) brings all the leadership perceptions of the players together in a visual leadership network, in which the best leaders in the team, based on the perceptions of their teammates, are positioned in the center. This information allows coaches to choose leaders that are accepted by all team members and as such allow the most effective implementation of a shared leadership approach.

Furthermore, regardless of the insight of the coach, providing a voice to the players has other benefits. More specifically, this procedure ensures that the appointed leaders experience the support of their teams as their selection relies on the perceptions of the players, instead of the coach. Realizing that their teammates not only accept, but also expect their leadership, will increase the motivation of the appointed leaders to take up their leadership responsibility and fulfill their role as good as possible (Cotterill \& Fransen, 2016). Using the perceptions of the players as basis for leadership appointment also infers that players who are not appointed as leaders will be less inclined to argue the decision.

\section{Strengths of the Study}

First, while previous studies on shared leadership in sports teams are mostly qualitative in nature or rely on a limited number of sports teams, the present study complements this research by providing a large quantitative data collection of 64 sports teams (840 players and coaches), stratified across sports, male and female teams, and competitive level, which allowed us for the first time to compare the densities and centralizations of the leadership networks in sports teams on a larger scale.

Second, while previous studies in both non-sporting organizations and sports teams mostly focused on density as a single indicator of shared leadership, we studied the 
combination of density and centralization, thereby providing full insight in the team's leadership structure.

Third, while previous studies on athlete leadership have often focused on the team captain, the present study used social network analyses to map the actual leadership structure in the team, as perceived by both coaches and players.

Furthermore, we went beyond leadership in general and investigated leadership across four leadership roles, both on the field (task and motivational leadership) and off the field (social and external leadership). The differential findings indicate that is important to make this distinction.

\section{Limitations and Avenues for Further Research}

Besides the strengths of our study, we acknowledge the following limitations that are inherent to the study design. First, our study was cross-sectional in nature and therefore did not warrant to draw any causal conclusions. Although an overall positive relationship was found between structures of shared leadership and the perceptions of the coach's leadership quality, we could not verify the direction of this relationship. It is possible that coaches become better coaches by implementing a shared leadership structure. However, it is also possible is that in teams with high-quality shared leadership, athletes will take up more responsibility and as such cover potential weaknesses of the coach, as a result of which the coach is perceived as best leader. In order to bring clarity in this matter, future research should adopt a longitudinal intervention study design in which coaches are asked to implement a structure of shared leadership, while the leadership quality of the coach is being tracked over time.

Second, given that our key variables to answer our first research question are variables at the team level (i.e., network density, network centralization, and coaches' leadership quality), the power of our sample is still quite low (e.g., to conduct a reliable comparison of 
our first research question between the different sports). Although future research could strive for an even bigger sample, the high response rate necessary to conduct social network analyses requires paper-and-pencil method (as this method has proven to be more effective than online questionnaires) and as such a large time investment.

Third, the present study relied on data collected in the Flemish sporting landscape (Belgium) and therefore does not take into account multicultural differences in leadership perceptions (Dickson, Castaño, Magomaeva, \& Den Hartog, 2012). For example, while Belgian players might greatly appreciate an autonomy-supportive coach, this might not hold for eastern cultures in which a controlling coaching style with less room for shared leadership might be more appreciated by the players. An interesting avenue for future research would therefore be to examine the same research questions in other countries and see whether our findings also hold across multiple cultures.

Fourth, we have only studied one of the barriers that potentially withhold coaches from implementing a structure of shared leadership. Besides the fear for devaluation of their own leadership quality, which based on our study findings is unjustified, a number of other potential barriers exist. Examples are the lack of knowledge on the benefits of shared leadership, the fear of losing control and creating chaos in the team, the fear of the reactions of club management or fans, the idea that players prefer a directive coaching style, the fear of losing visibility as a leader, etc. In order to change the hierarchical structure in the Flemish sports landscape to a culture inspired by shared leadership, it is essential to gain profound insight in all barriers that withhold coaches from empowering their players. A qualitative study in which coaches are questioned about the reasons not to empower the players in their team would provide very valuable information in this matter and could inspire future research studies in this area. 
As a fifth and final limitation, we concede that appointing the best leaders within the team on the four leadership roles constitutes only a first, though crucial step towards an effective structure of shared leadership. Given the observed importance of the average leadership quality in the team, it is essential in a second phase to further develop the leadership qualities of the appointed leaders (Gould \& Voelker, 2010; Gould et al., 2013). Although there are ample development programs for coaches, leadership programs for the athlete leaders within the team are sparse (Blanton, Sturges, \& Gould, 2014; Cotterill, 2017). An interesting avenue for future research would be to design leadership programs aiming to further develop the appointed leaders in their specific leadership role.

\section{Conclusion}

We can conclude that adopting a shared leadership approach does not diminish the coaches' own leadership quality from the perspective of their players. In contrast, teams in which more players are engaged in team leadership perceive their coaches to be better leaders. These results suggest that by empowering the players within the team, the coach's own leadership becomes even more appreciated by the players. In order to implement such a structure of shared leadership, it important to identify the best leaders in the team. The study findings suggest that, in order to make the right selection of leaders, coaches are better served by involving their players in the leadership decision-making process. Then only when the appointed athlete leaders have the support from the entire team can their leadership be most effective. In short, coaches have a chance to become great leaders, not because of their power, but because of their ability to empower others. 


\section{References}

Arthur, C. A., \& Lynn, A. (2017). Transformational leadership and the role of the coach. In R. Thelwell, C. Harwood, \& I. Greenlees (Eds.), The psychology of sports coaching: Research and practice (pp. 187-202). Abingdon, UK: Routledge.

Arthur, C. A., Wagstaff, C. R. D., \& Hardy, L. (2017). Leadership in sport organizations. In C. R. D. Wagstaff (Ed.), The organizational psychology of sport: Key issues and practical applications (pp. 153-175). Abingdon, UK: Routledge.

Bartram, T., \& Casimir, G. (2007). The relationship between leadership and follower in-role performance and satisfaction with the leader: The mediating effects of empowerment and trust in the leader. Leadership \& Organization Development Journal, 28(1), 4-19. doi:10.1108/01437730710718218

Blanton, J. E., Sturges, A. J., \& Gould, D. (2014). Lessons learned from a leadership development club for high school athletes. Journal of Sport Psychology in Action, 5(1), 1-13. doi:10.1080/21520704.2013.848827

Blau, P. M. (1964). Exchange and power in social life. New York: Wiley.

Carson, J. B., Tesluk, P. E., \& Marrone, J. A. (2007). Shared leadership in teams: An investigation of antecedent conditions and performance. Academy of Management Journal, 50(5), 1217-1234. doi:10.2307/20159921

Chelladurai, P., \& Riemer, H. A. (1998). Measurement of leadership in sport. In J. L. Duda (Ed.), Advances in sport and exercise psychology measurement (pp. 227-253).

Morgantown, WV: Fitness Information Technologies.

Cotterill, S. T. (2017). Developing leadership skills in sport: A case study of elite cricketers. Case Studies in Sport and Exercise Psychology, 1(1), 16-25. doi:10.1123/cssep.20160004 
Cotterill, S. T., \& Fransen, K. (2016). Athlete leadership in sport teams: Current understanding and future directions. International Review of Sport and Exercise Psychology, 9(1), 116-133. doi:10.1080/1750984X.2015.1124443

Crozier, A. J., Loughead, T. M., \& Munroe-Chandler, K. J. (2013). Examining the benefits of athlete leaders in sport. Journal of Sport Behavior, 36(4), 346-364.

Cushion, C., Ford, P. R., \& Williams, A. M. (2012). Coach behaviours and practice structures in youth soccer: Implications for talent development. Journal of Sports Sciences, 30(15), 1631-1641. doi:10.1080/02640414.2012.721930

D’Innocenzo, L., Mathieu, J. E., \& Kukenberger, M. R. (2016). A meta-analysis of different forms of shared leadership-team performance relations. Journal of Management, 42(7), 1964-1991. doi:10.1177/0149206314525205

Day, D. V., Gordon, S., \& Fink, C. (2012). The sporting life: Exploring organizations through the lens of sport. Academy of Management Annals, 6(1), 397-433. doi:10.1080/19416520.2012.678697

De Backer, M., Boen, F., Ceux, T., De Cuyper, B., Hoigaard, R., Callens, F., . . V Vande Broek, G. (2011). Do perceived justice and need support of the coach predict team identification and cohesion? Testing their relative importance among top volleyball and handball players in Belgium and Norway. Psychology of Sport and Exercise, 12(2), 192-201. doi:10.1016/j.psychsport.2010.09.009

Delrue, J., Reynders, B., Vande Broek, G., Aelterman, N., De Backer, M., Decroos, S., . . . Vansteenkiste, M. (2019). Adopting a helicopter-perspective towards motivating and demotivating coaching: A circumplex approach. Psychology of Sport and Exercise, 40, 110-126. doi:10.1016/j.psychsport.2018.08.008 
Dickson, M. W., Castaño, N., Magomaeva, A., \& Den Hartog, D. N. (2012). Conceptualizing leadership across cultures. Journal of World Business, 47(4), 483-492. doi:10.1016/j.jwb.2012.01.002

Eys, M. A., Loughead, T. M., \& Hardy, J. (2007). Athlete leadership dispersion and satisfaction in interactive sport teams. Psychology of Sport and Exercise, 8(3), 281296. doi:10.1016/j.psychsport.2006.04.005

Fletcher, D., \& Arnold, R. (2015). Performance leadership and management in elite sport: Current status and future directions. In S. Andersen, B. Houlihan, \& L. T. Ronglan (Eds.), Managing elite sport systems: Research and practice (pp. 162-181). Abingdon, UK: Routledge.

Fransen, K., Boen, F., Vansteenkiste, M., Mertens, N., \& Vande Broek, G. (2018). The power of competence support: The impact of coaches and athlete leaders on intrinsic motivation and performance. Scandinavian Journal of Medicine and Science in Sports, 28, 725-745. doi:10.1111/sms. 12950

Fransen, K., Decroos, S., Vande Broek, G., \& Boen, F. (2016a). Leading from the top or leading from within? A comparison between coaches' and athletes' leadership as predictors of team identification, team confidence, and team cohesion. International Journal of Sports Science \& Coaching, 11(6), 757-771. doi:10.1177/1747954116676102

Fransen, K., Delvaux, E., Mesquita, B., \& Van Puyenbroeck, S. (2018). The emergence of shared leadership in newly formed teams with an initial structure of vertical leadership: A longitudinal analysis. The Journal of Applied Behavioral Science, 54(2), 140-170. doi:10.1177/0021886318756359

Fransen, K., Haslam, S. A., Mallett, C. J., Steffens, N. K., Peters, K., \& Boen, F. (2016b). Leading from the centre: A comprehensive examination of the relationship between 
central playing positions and leadership in sport. PLOS ONE, 11(12), e0168150. doi:10.1371/journal.pone.0168150

Fransen, K., Haslam, S. A., Mallett, C. J., Steffens, N. K., Peters, K., \& Boen, F. (2017). Is perceived athlete leadership quality related to team effectiveness? A comparison of three professional sports teams. Journal of Science and Medicine in Sport, 20, 800806. doi:10.1016/j.jsams.2016.11.024

Fransen, K., Van Puyenbroeck, S., Loughead, T. M., Vanbeselaere, N., De Cuyper, B., Vande Broek, G., \& Boen, F. (2015a). The art of athlete leadership: Identifying high-quality leadership at the individual and team level through Social Network Analysis. Journal of Sport \& Exercise Psychology, 37(3), 274-290. doi:10.1123/jsep.2014-0259

Fransen, K., Van Puyenbroeck, S., Loughead, T. M., Vanbeselaere, N., De Cuyper, B., Vande Broek, G., \& Boen, F. (2015b). Who takes the lead? Social network analysis as pioneering tool to investigate shared leadership within sports teams. Social Networks, 43, 28-38. doi:10.1016/j.socnet.2015.04.003

Fransen, K., Vanbeselaere, N., De Cuyper, B., Vande Broek, G., \& Boen, F. (2014). The myth of the team captain as principal leader: Extending the athlete leadership classification within sport teams. Journal of Sports Sciences, 32(14), 1389-1397. doi:10.1080/02640414.2014.891291

Gibb, C. A. (1954). Leadership. In G. Lindzey (Ed.), Handbook of social psychology (Vol. 2, pp. 877-917). Reading, MA: Addison-Wesley.

Gockel, C., \& Werth, L. (2010). Measuring and modeling shared leadership: Traditional approaches and new ideas. Journal of Personnel Psychology, 9(4), 172-180. doi:10.1027/1866-5888/a000023 
Gould, D., \& Voelker, D. K. (2010). Youth sport leadership development: Leveraging the sports captaincy experience. Journal of Sport Psychology in Action, 1(1), 1-14. doi:10.1080/21520704.2010.497695

Gould, D., Voelker, D. K., \& Griffes, K. (2013). Best coaching practices for developing team captains. The Sport Psychologist, 27(1), 13-26. doi:10.1123/tsp.27.1.13

Gouldner, A. W. (1960). The norm of reciprocity: A preliminary statement. American Sociological Review, 25(2), 161-178. doi:10.2307/2092623

Gulak-Lipka, P. (2017). The role of trust for leadership in team sports. 2017, 3(3), 16. doi:10.12775/jcrl.2016.015

Hackman, J. R., \& Wageman, R. (2005). A theory of team coaching. Academy of Management Review, 30(2), 269-287.

Hampson, R., \& Jowett, S. (2014). Effects of coach leadership and coach- athlete relationship on collective efficacy. Scandinavian Journal of Medicine and Science in Sports, 24(2), 454-460. doi:10.1111/j.1600-0838.2012.01527.x

Hoppe, B., \& Reinelt, C. (2010). Social network analysis and the evaluation of leadership networks. The Leadership Quarterly, 21(4), 600-619. doi:10.1016/j.leaqua.2010.06.004

Huang, J. T. (2012). Be proactive as empowered? The role of trust in one's supervisor in psychological empowerment, feedback seeking, and job performance. Journal of Applied Social Psychology, 42(S1), E103-E127. doi:10.1111/j.15591816.2012.01019.x

Little, J. W. (1995). Contested ground: The basis of teacher leadership in two restructuring high schools. The Elementary School Journal, 96(1), 47-63.

Loughead, T. M., Fransen, K., Van Puyenbroeck, S., Hoffmann, M. D., \& Boen, F. (2016). An examination of the relationship between athlete leadership and cohesion using 
social network analysis. Journal of Sports Sciences, 34(21), 2063-2073. doi:10.1080/02640414.2016.1150601

Loughead, T. M., Hardy, J., \& Eys, M. A. (2006). The nature of athlete leadership. Journal of Sport Behavior, 29, 142-158.

Mallett, C. J., \& Lara-Bercial, S. (2016). Serial winning coaches: People, vision and environment. In M. Raab, P. Wylleman, R. Seiler, A.-M. Elbe, \& A. Hatzigeorgiadis (Eds.), Sport and exercise psychology research: Theory to practice (pp. 289-322). Amsterdam: Elsevier.

Mayo, M., Meindl, J. R., \& Pastor, J. (2003). Shared leadership in work teams: A social network approach. In C. L. Pearce \& J. A. Conger (Eds.), Shared leadership: Reframing the hows and whys of leadership (pp. 193-214): Sage.

Morgan, P. B. C., Fletcher, D., \& Sarkar, M. (2013). Defining and characterizing team resilience in elite sport. Psychology of Sport and Exercise, 14(4), 549-559. doi:10.1016/j.psychsport.2013.01.004

Moye, M. J., \& Henkin, A. B. (2006). Exploring associations between employee empowerment and interpersonal trust in managers. Journal of Management Development, 25(2), 101-117. doi:10.1108/02621710610645108

Moye, M. J., Henkin, A. B., \& Egley, R. J. (2005). Teacher-principal relationships: Exploring linkages between empowerment and interpersonal trust. Journal of Educational Administration, 43(3), 260-277. doi:10.1108/09578230510594796

Muijs, D., \& Harris, A. (2003). Teacher leadership_-Improvement through empowerment? An overview of the literature. Educational Management \& Administration, 31(4), 437448. doi:10.1177/0263211x030314007 
Ntoumanis, N., \& Mallett, C. J. (2014). Motivation in sport. In A. G. H. D. Papaioannou (Ed.), Routledge Companion to Sport and Exercise Psychology (pp. 67-82). London: Taylor and Francis.

Pearce, C. L., \& Conger, J. A. (Eds.). (2003). Shared leadership: Reframing the hows and whys of leadership. Thousand Oaks, CA: Sage.

Sallee, A., \& Flaherty, K. (2003). Enhancing salesperson trust: An examination of managerial values, empowerment, and the moderating influence of SBU strategy. Journal of Personal Selling \& Sales Management, 23(4), 299-310. doi:10.1080/08853134.2003.10749005

Shaver, K. G. (1975). An introduction to attribution processes. Cambridge, MA: Winthrop.

Small, E. E., \& Rentsch, J. R. (2010). Shared leadership in teams: A matter of distribution. Journal of Personnel Psychology, 9(4), 203-211. doi:10.1027/1866-5888/a000017

Sparrowe, R. T., Liden, R. C., Wayne, S. J., \& Kraimer, M. L. (2001). Social networks and the performance of individuals and groups. Academy of Management Journal, 44(2), 316-325. doi:10.2307/3069458

Thelwell, R. C., Wagstaff, C. R. D., Rayner, A., Chapman, M., \& Barker, J. (2017). Exploring athletes' perceptions of coach stress in elite sport environments. Journal of Sports Sciences, 35(1), 44-55. doi:10.1080/02640414.2016.1154979

Van Puyenbroeck, S., Stouten, J., \& Vande Broek, G. (2018). Coaching is teamwork! The role of need-supportive coaching and the motivational climate in stimulating proactivity in volleyball teams. Scandinavian Journal of Medicine and Science in Sports, 28(1), 319328. doi:10.1111/sms.12895

Vroom, V. H., \& Yetton, P. W. (1973). Leadership and decision-making. Pittsburgh: University of Pittsburgh Press. 
Weinberg, R., \& McDermott, M. (2002). A comparative analysis of sport and business organizations: Factors perceived critical for organizational success. Journal of Applied Sport Psychology, 14(4), 282-298. doi:10.1080/10413200290103563

Welty Peachey, J., Zhou, Y., Damon, Z. J., \& Burton, L. J. (2015). Forty years of leadership research in sport management: A review, synthesis, and conceptual framework. Journal of Sport Management, 29(5), 570-587. doi:10.1123/jsm.2014-0126

Wheatley, M. (1997). Goodbye, Command and Control. Leader to Leader, 1997(5), 21-28. doi:10.1002/1tl.40619970507

Whitener, E. M., Brodt, S. E., Korsgaard, M. A., \& Werner, J. M. (1998). Managers as initiators of trust: An exchange relationship framework for understanding managerial trustworthy behavior. The Academy of Management Review, 23(3), 513-530. doi:10.2307/259292

Zhu, W., May, D. R., \& Avolio, B. J. (2004). The impact of ethical leadership behavior on employee outcomes: The roles of psychological empowerment and authenticity. Journal of Leadership \& Organizational Studies, 11(1), 16-26. doi:10.1177/107179190401100104 
Table 1. The definition of the four leadership roles occupied by athlete leaders (Fransen,

Vanbeselaere, De Cuyper, Vande Broek, \& Boen, 2014).

\begin{tabular}{|c|c|}
\hline Leadership role & Definition \\
\hline Task leader & $\begin{array}{l}\text { A task leader is in charge on the field; this person helps his team to focus } \\
\text { on the team goals and helps in tactical decision making. Furthermore, the } \\
\text { task leader gives his teammates tactical advice during the game and gives } \\
\text { them guidance if necessary. }\end{array}$ \\
\hline $\begin{array}{l}\text { Motivational } \\
\text { leader }\end{array}$ & $\begin{array}{l}\text { The motivational leader is the biggest motivator on the field; this person } \\
\text { encourages teammates to go to any extreme; this leader also puts fresh } \\
\text { heart into athletes who are discouraged. In short, this leader steers all the } \\
\text { emotions on the field in the right direction in order to maximize team } \\
\text { performance. }\end{array}$ \\
\hline Social leader & $\begin{array}{l}\text { The social leader has a leading role off the field; this person promotes } \\
\text { good relations within the team and cares about having a good team } \\
\text { atmosphere, for example, in the dressing room, on the bus, or during } \\
\text { social activity. Furthermore, this leader helps with conflicts between } \\
\text { teammates off the field. They are a good listener and are trusted by their } \\
\text { teammates. }\end{array}$ \\
\hline External leader & $\begin{array}{l}\text { The external leader is the link between his team and the people outside the } \\
\text { team; this leader is the representative of the team when dealing with the } \\
\text { club management. If communication is needed with media or sponsors, } \\
\text { this person will take the lead. This leader will also communicate the views } \\
\text { of the club management to the team, for example, regarding sponsoring, } \\
\text { club events, and contracts. }\end{array}$ \\
\hline
\end{tabular}


Table 2. Correlations between Coaches’ Leadership Quality and Leadership Network

Indicators

\begin{tabular}{llllllllllll}
$M$ & $S D$ & 1. & 2. & 3. & 4. & 5. & 6. & 7. & 8. & 9. & 10. \\
\hline
\end{tabular}

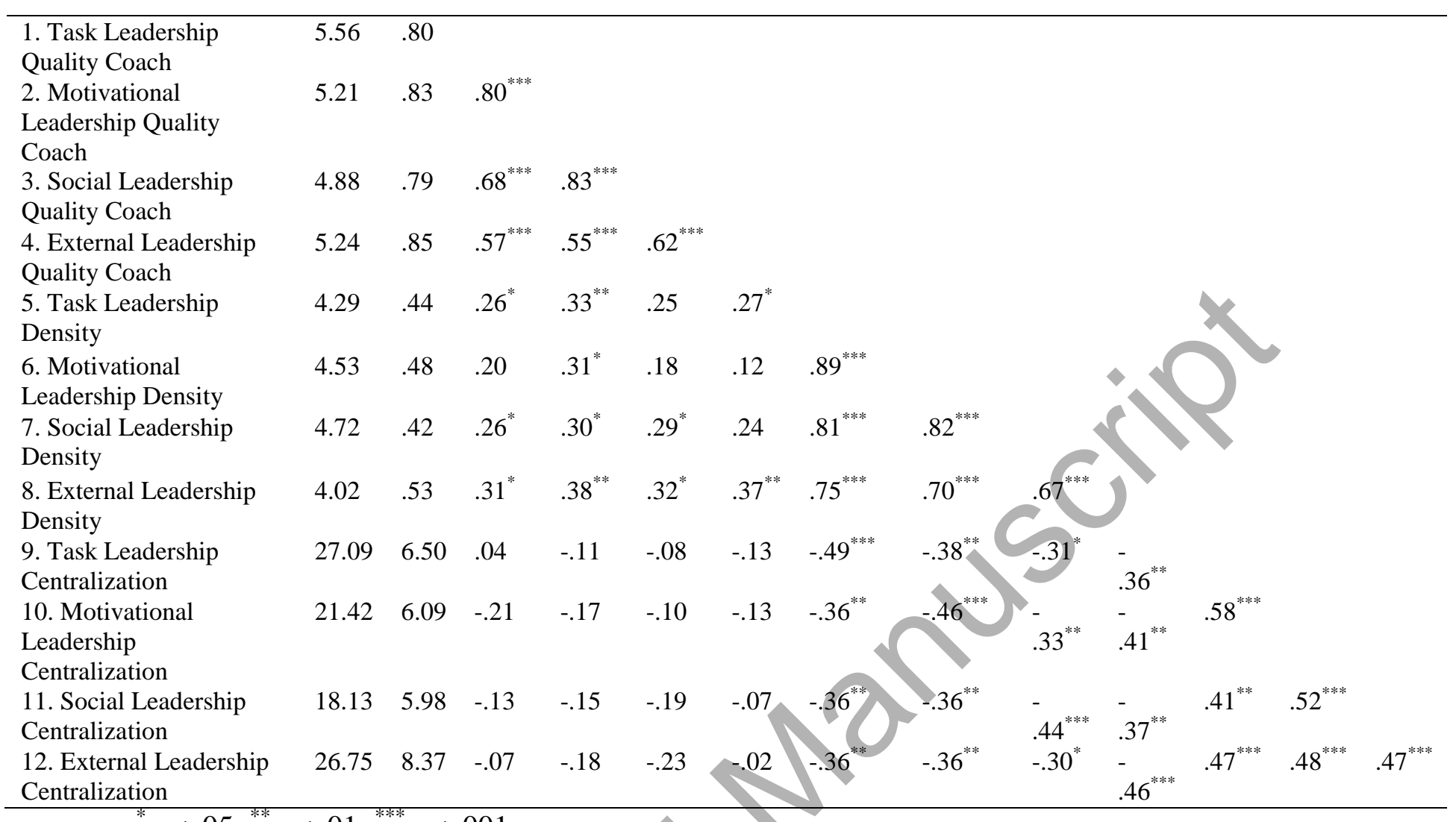


Table 3. Correlations between the leadership quality of the coach in a specific role and the associated network density and centralization for the same leadership role for each of the sports, male and female sports teams, and high and low competitive level.

\begin{tabular}{|c|c|c|c|c|c|c|c|c|}
\hline & \multicolumn{2}{|c|}{ Task leadership } & \multicolumn{2}{|c|}{ Motivational leadership } & \multicolumn{2}{|c|}{ Social leadership } & \multicolumn{2}{|c|}{ External leadership } \\
\hline $\begin{array}{l}\text { between coach } \\
\text { leadership quality } \\
\text { and... }\end{array}$ & Density & Centralization & Density & Centralization & Density & Centralization & Density & Centralization \\
\hline Complete dataset & $.26^{*}$ & .04 & $.31^{*}$ & -.17 & $.29^{*}$ & -.19 & $.37^{* *}$ & -.02 \\
\hline \multicolumn{9}{|l|}{ Sports } \\
\hline Soccer & .48 & -.02 & $.52^{*}$ & -.06 & $.65^{* *}$ & -.30 & .36 & .08 \\
\hline Volleyball & -.004 & -.07 & .13 & -.41 & .13 & -.04 & & -.05 \\
\hline Basketball & .04 & .01 & .21 & -.19 & .06 & -.10 & & .17 \\
\hline Handball & .23 & .29 & .16 & .11 & .39 & & & -.10 \\
\hline \multicolumn{9}{|l|}{ Team sex } \\
\hline Male teams & .17 & .12 & .26 & .09 & .32 & -.2 & .18 & .31 \\
\hline Female teams & $.36^{*}$ & -.07 & $.38^{*}$ & -.33 & & -.24 & $.46^{*}$ & -.46 \\
\hline \multicolumn{9}{|l|}{ Competitive level } \\
\hline High level & .22 & -.07 & .04 & & 04 & -.07 & .29 & -.06 \\
\hline Low level & .34 & .22 & $.49^{* *}$ & .12 & $.46^{*}$ & -.23 & $.40^{*}$ & .02 \\
\hline
\end{tabular}

$$
{ }^{*} p<.05 ;{ }^{* * *} p<.01 ;{ }^{* * *} p<.001 .
$$


Table 4. Means and standard deviations (in parentheses) for the leadership quality of coaches on a specific leadership role, presented according to the leadership structure in their team for that specific role. The leadership structure that is associated with the highest leadership quality of the coaches is highlighted in bold.

\begin{tabular}{|c|c|c|c|c|}
\hline & $\begin{array}{l}\text { High Density - } \\
\text { Moderate } \\
\text { Centralization }\end{array}$ & $\begin{array}{l}\text { High Density - Low } \\
\text { Centralization }\end{array}$ & $\begin{array}{c}\text { Low Density - } \\
\text { Moderate } \\
\text { Centralization }\end{array}$ & $\begin{array}{l}\text { Low Density - Low } \\
\text { Centralization }\end{array}$ \\
\hline Task Leadership & $(N=10)$ & $(N=21)$ & $(N=22)$ & $(N=9)$ \\
\hline Complete dataset & $5.68(1.06)$ & $5.65(.71)$ & $5.52(.81)$ & $5.33(.74)$ \\
\hline \multicolumn{5}{|l|}{ Team sex } \\
\hline Male teams & $5.84(.88)$ & $5.62(.82)$ & $5.67(.74)$ & $5.53(.41)$ \\
\hline Female teams & $5.43(1.40)$ & $5.66(.68)$ & $5.30(.89)$ & $5.16(.95)$ \\
\hline \multicolumn{5}{|l|}{ Competitive level } \\
\hline High level & $5.24(1.14)$ & $5.47(.65)$ & $5.24(.88)$ & (.כ. \\
\hline Low level & $6.33(.52)$ & $5.84(.77)$ & $5.80(.65)$ & $5.33(1.00)$ \\
\hline Motivational Leadership & $(N=14)$ & $(N=17)$ & $(N=17)$ & $(N=14)$ \\
\hline Complete dataset & $5.48(.85)$ & $5.25(.88)$ & $(.98)$ & $5.21(.48)$ \\
\hline \multicolumn{5}{|l|}{ Team sex } \\
\hline Male teams & $5.55(.79)$ & $5.12(.76)$ & & $5.10(.46)$ \\
\hline Female teams & $5.38(1.00)$ & $5.31(.97)$ & $4.60(.98)$ & $5.49(.46)$ \\
\hline \multicolumn{5}{|l|}{ Competitive level } \\
\hline High level & $5.02(.65)$ & 10 & $4.75(.96)$ & $5.25(.46)$ \\
\hline Low level & $6.30(.42)$ & $5.33(1.00)$ & $5.21(1.00)$ & $5.18(.52)$ \\
\hline Social Leadership & $(N=11)$ & $(N$ & $(N=20)$ & $(N=10)$ \\
\hline Complete dataset & 5.13 & $4.97(.93)$ & $4.71(.79)$ & $4.73(.56)$ \\
\hline \multicolumn{5}{|l|}{ Team sex } \\
\hline Male teams & 1) & $5.19(.82)$ & $4.84(.69)$ & $5.17(.15)$ \\
\hline Female teams & 2) & $4.80(1.02)$ & $4.51(.94)$ & $4.55(.58)$ \\
\hline \multicolumn{5}{|l|}{ Competitive level } \\
\hline High level & $5.16(.59)$ & $4.41(.88)$ & $4.49(.80)$ & $4.78(.55)$ \\
\hline Low level & $5.09(.87)$ & $5.48(.67)$ & $4.94(.76)$ & $4.66(.65)$ \\
\hline External Leadership & $(N=12)$ & $(N=20)$ & $(N=20)$ & $(N=10)$ \\
\hline Complete dataset & $5.34(.75)$ & $5.39(.79)$ & $5.12(1.04)$ & $5.07(.72)$ \\
\hline \multicolumn{5}{|l|}{ Team sex } \\
\hline Male teams & $5.50(.49)$ & $5.43(.65)$ & $5.65(.64)$ & $5.09(.48)$ \\
\hline Female teams & $5.22(.91)$ & $5.35(.97)$ & $4.68(1.13)$ & $5.04(1.08)$ \\
\hline \multicolumn{5}{|l|}{ Competitive level } \\
\hline High level & $5.16(.94)$ & $5.24(.94)$ & $4.88(.88)$ & $4.96(.67)$ \\
\hline Low level & $5.52(.51)$ & $5.52(.66)$ & $5.35(1.18)$ & $5.32(.91)$ \\
\hline
\end{tabular}


Note. The analyses for the four sports are not reported since the number of teams per category was too limited and sometimes even zero.

Table 5. Correlations between the perceptions of teammates and the perceptions of the coach on a player's leadership quality on each of the four roles.

\begin{tabular}{|c|c|c|c|c|}
\hline & $\begin{array}{c}\text { Task } \\
\text { leadership }\end{array}$ & $\begin{array}{l}\text { Motivational } \\
\text { leadership }\end{array}$ & $\begin{array}{c}\text { Social } \\
\text { leadership }\end{array}$ & $\begin{array}{c}\text { External } \\
\text { leadership }\end{array}$ \\
\hline Complete dataset & $.61^{* * *}$ & $.54^{* * *}$ & $.52^{* * *}$ & \\
\hline \multicolumn{5}{|l|}{ Sports } \\
\hline Soccer & $.58^{* * * *}$ & $.43^{* * * *}$ & $.53^{* * * *}$ & \\
\hline Volleyball & $.67^{* * * *}$ & $.66^{* * * *}$ & & $.62^{*}$ \\
\hline Basketball & $.58^{* * *}$ & $.58^{* * *}$ & & $.51^{* * *}$ \\
\hline Handball & $.60^{* * *}$ & $.50^{* * * *}$ & & $.60^{* * *}$ \\
\hline \multicolumn{5}{|l|}{ Team sex } \\
\hline Male teams & $.70^{* * *}$ & & $.60^{* * *}$ & $.59^{* * *}$ \\
\hline Female teams & $.52^{* * *}$ & & $.44^{* * *}$ & $.54^{* * *}$ \\
\hline \multicolumn{5}{|l|}{ Competitive level } \\
\hline High level & & $.57^{* * *}$ & $.57^{* * *}$ & $.52^{* * *}$ \\
\hline Low level & & $.51^{* * * *}$ & $.49^{* * *}$ & $.60^{* * *}$ \\
\hline
\end{tabular}


Table 6. Cross table reporting the number of best leaders as perceived by the coach that are perceived as best, second best, third best leader by the players or not even included in the player top 3 .

\begin{tabular}{|c|c|c|c|c|c|}
\hline $\begin{array}{l}\text { Best leaders as } \\
\text { perceived by the coach }\end{array}$ & $\begin{array}{c}N \\
\text { Number of best } \\
\text { leaders as indicated } \\
\text { by the coach }\end{array}$ & $\begin{array}{l}\text { Best leader as } \\
\text { perceived by } \\
\text { the players }\end{array}$ & $\begin{array}{c}\text { Second best } \\
\text { leader as } \\
\text { perceived by the } \\
\text { players }\end{array}$ & $\begin{array}{c}\text { Third best leader as } \\
\text { perceived by the } \\
\text { players }\end{array}$ & $\begin{array}{c}\text { Outside the } \\
\text { Player-rated } \\
\text { Top } 3\end{array}$ \\
\hline Task leadership & $117(15 \%)$ & $39(33.3 \%)$ & $25(21.4 \%)$ & $15(12.8 \%)$ & $38(32.5 \%)$ \\
\hline \multicolumn{6}{|l|}{ Sports } \\
\hline Soccer & $37(15.0 \%)$ & $9(24.3 \%)$ & $10(27.0 \%)$ & $4(10.8 \%)$ & $14(37.8 \%)$ \\
\hline Volleyball & $28(17.4 \%)$ & $13(46.4 \%)$ & $6(21.4 \%)$ & $3(10.7 \%)$ & $6(21.4 \%)$ \\
\hline Basketball & $20(14.9 \%)$ & $7(35.0 \%)$ & $3(15.0 \%)$ & $4(20.0 \%)$ & $6(30.0 \%)$ \\
\hline Handball & $32(13.7 \%)$ & $10(31.3 \%)$ & $6(18.8 \%)$ & $4(12.5 \%)$ & $12(37.5 \%)$ \\
\hline \multicolumn{6}{|l|}{ Team sex } \\
\hline Male teams & $62(16.3 \%)$ & $22(35.5 \%)$ & $13(21.0 \%)$ & $9(14.5 \%)$ & $18(29.0 \%)$ \\
\hline Female teams & $55(13.9 \%)$ & $17(30.9 \%)$ & $12(21.8 \%)$ & $6(10.9 \%)$ & $20(36.4 \%)$ \\
\hline \multicolumn{6}{|l|}{ Competitive level } \\
\hline High level & $55(12.9 \%)$ & $20(36.4 \%)$ & $13(23.6 \%)$ & $6(10.9 \%)$ & $16(29.1 \%)$ \\
\hline Low level & $62(17.8 \%)$ & $19(30.6 \%)$ & $12(19.4 \%)$ & $9(14.5 \%)$ & $22(35.5 \%)$ \\
\hline $\begin{array}{l}\text { Motivational } \\
\text { leadership }\end{array}$ & $129(17 \%)$ & $37(28.7 \%)$ & $0.9 \%)$ & $21(16.3 \%)$ & $44(34.1 \%)$ \\
\hline \multicolumn{6}{|l|}{ Sports } \\
\hline Soccer & $44(17.8 \%)$ & $12(27.3 \%)$ & $10(22.7 \%)$ & $5(11.4 \%)$ & $17(38.6 \%)$ \\
\hline Volleyball & $32(19.9 \%)$ & $12(37.5 \%)$ & $6(18.8 \%)$ & $6(18.8 \%)$ & $8(25.0 \%)$ \\
\hline Basketball & $22(16.4 \%)$ & $8(36.4 \%)$ & $5(22.7 \%)$ & $2(9.1 \%)$ & $7(31.8 \%)$ \\
\hline Handball & $31(13.2 \%)$ & $5(16.1 \%)$ & $6(19.4 \%)$ & $8(25.8 \%)$ & $12(38.7 \%)$ \\
\hline \multicolumn{6}{|l|}{ Team sex } \\
\hline Male teams & $73(19.2 \%)$ & $20(27.4 \%)$ & $18(24.7 \%)$ & $9(12.3 \%)$ & $26(35.6 \%)$ \\
\hline Female teams & $56(14.1 \%)$ & $17(30.4 \%)$ & $9(16.1 \%)$ & $12(21.4 \%)$ & $18(32.1 \%)$ \\
\hline \multicolumn{6}{|l|}{ Competitive level } \\
\hline High level & $70(16.4 \%)$ & $22(31.4 \%)$ & $15(21.4 \%)$ & $10(14.3 \%)$ & $23(32.9 \%)$ \\
\hline Low level & $59(17.0 \%)$ & $15(25.4 \%)$ & $12(20.3 \%)$ & $11(18.6 \%)$ & $21(35.6 \%)$ \\
\hline Social leadership & $160(21 \%)$ & $38(23.8 \%)$ & $28(17.5 \%)$ & $23(14.4 \%)$ & $71(44.4 \%)$ \\
\hline \multicolumn{6}{|l|}{ Sports } \\
\hline Soccer & $39(15.8 \%)$ & $11(28.2 \%)$ & $6(15.4 \%)$ & $3(7.7 \%)$ & $19(48.7 \%)$ \\
\hline Volleyball & $45(28.0 \%)$ & $12(26.7 \%)$ & $8(17.8 \%)$ & $9(20.0 \%)$ & $16(35.6 \%)$ \\
\hline Basketball & $43(32.1 \%)$ & $9(20.9 \%)$ & $8(18.6 \%)$ & $7(16.3 \%)$ & $19(44.2 \%)$ \\
\hline Handball & $33(14.1 \%)$ & $6(18.2 \%)$ & $6(18.2 \%)$ & $4(12.1 \%)$ & $17(51.5 \%)$ \\
\hline \multicolumn{6}{|l|}{ Team sex } \\
\hline Male teams & $81(21.3 \%)$ & $21(25.9 \%)$ & $15(18.5 \%)$ & $12(14.8 \%)$ & $33(40.7 \%)$ \\
\hline Female teams & $79(19.9 \%)$ & $17(21.5 \%)$ & $13(16.5 \%)$ & $11(13.9 \%)$ & $38(48.1 \%)$ \\
\hline \multicolumn{6}{|l|}{ Competitive level } \\
\hline High level & $60(14.0 \%)$ & $18(30.0 \%)$ & $11(18.3 \%)$ & $8(13.3 \%)$ & $23(38.3 \%)$ \\
\hline Low level & $100(28.7 \%)$ & $20(20.0 \%)$ & $17(17.0 \%)$ & $15(15.0 \%)$ & $48(48.0 \%)$ \\
\hline External leadership & $128(16 \%)$ & $43(33.6 \%)$ & $26(20.3 \%)$ & $21(16.4 \%)$ & $38(29.7 \%)$ \\
\hline
\end{tabular}


Sports

$\begin{array}{lccccc}\text { Soccer } & 51(20.6 \%) & 13(25.5 \%) & 9(17.6 \%) & 7(13.7 \%) & 22(43.1 \%) \\ \text { Volleyball } & 30(18.6 \%) & 13(43.3 \%) & 9(30.0 \%) & 7(23.3 \%) & 1(3.3 \%) \\ \text { Basketball } & 26(19.4 \%) & 8(30.8 \%) & 5(19.2 \%) & 4(15.4 \%) & 9(34.6 \%) \\ \text { Handball } & 21(9.0 \%) & 9(42.8 \%) & 3(14.3 \%) & 3(14.3 \%) & 6(28.6 \%)\end{array}$

Team sex

\begin{tabular}{lccccc} 
Male teams & $54(14.2 \%)$ & $21(38.9 \%)$ & $13(24.1 \%)$ & $8(14.8 \%)$ & $12(22.2 \%)$ \\
Female teams & $74(18.7 \%)$ & $22(29.7 \%)$ & $13(17.6 \%)$ & $13(17.6 \%)$ & $26(35.1 \%)$ \\
mpetitive level & & & & & \\
High level & $55(12.9 \%)$ & $24(43.6 \%)$ & $13(23.6 \%)$ & $10(18.2 \%)$ & $8(14.5 \%)$ \\
Low level & $73(21.0 \%)$ & $19(26.0 \%)$ & $13(17.8 \%)$ & $11(15.1 \%)$ & $30(41.1 \%)$ \\
\hline
\end{tabular}

